\title{
COMPARATIVE ANALYSIS OF THE CHARACTERISTICS OF PHYSICAL ABILITY OF 14-15 YEARS OLD STUDENTS
}

\author{
M. Borukova ${ }^{1^{*}}$, P. Mavrudiev ${ }^{2}$ \\ ${ }^{1}$ Faculty of Pedagogy, National Sports Academy „Vassil Levski“, Sofia, Bulgaria \\ ${ }^{2}$ Department of Theory and Methodology of Physical Education, National Sports Academy „Vassil \\ Levski“, Sofia, Bulgaria
}

\begin{abstract}
PURPOSE of the study is revealing the level of physical activity of 14-15 year olds, to establish differences in the level of physical abilities between classes and genders to be able to improve the learning process in physical education in secondary school. METHODS: 36 students from one school were tested against 5 indicators, bearing information on the major signs of physical preparedness: running 30m; two-foot-long jump from a place; throwing a tight ball $3 \mathrm{~kg}$. with two hands over head from standing; running $200 \mathrm{~m}$; a test of agility and coordination. Statistical analyzes were performed with SPSS23 and variation and comparative analysis were made, Student tcriterion and Mann-Whitney U-criterion were used. A sigmatic evaluation method was also applied. RESULTS are indicating, that in the population surveyed, the differences in the studied parameters are only by gender and are in favour of boys, the differences are statistically significant and supported by 95 percent guarantee probability.

CONCLUSIONS: It has been found that in this age group, gender differences have a major impact on the physical capacity of students, which requires teachers to carefully select, apply and dosage physical education tools when working at PE classes.
\end{abstract}

Key words: teaching, secondary school, girls, boys

\section{INTRODUCTION}

In our time, the problem of preserving and strengthening the physical and mental health of the younger generation is particularly relevant. The introduction of modern technologies in all spheres of life has resulted in minimal motor activity. Immobility, coupled with unhealthy eating, has led to lasting physiological changes in the growing Bulgarian population. National statistical surveys conducted in recent years show that $80 \%$ of children in the Republic of Bulgaria in childhood and adolescence suffer from overweight and obesity, flat feet, spinal distortions, etc. Over time, this physiological imbalance has led to cardiovascular disease, mental disorders, musculoskeletal disorders, and more.

\footnotetext{
*Correspondence to: Mariana Borukova, National Sports Academy ,, Vassil Levski “, Facultet of Pedagogy, 1700, Sofia, Studentski grad, email: marianaborukova@gmail.com, mobile: 0893396552
}

Physical education and sport play a key role in limiting and eliminating the negative trends in this process. Opportunities for physical activity and participation in related activities are directly related to the students' health status. The modern and attractive sports base should be considered as a possibility for prevention against the unfavorable tendencies in the health of the adolescents, due to insufficient motor activity. The physical development and capacity of the younger generation are closely linked to health status, health promotion and increased vitality. Forming habits for systematic exercise and sports activities is an investment with long-term social, health and economic impact. The complex development of physical qualities poses the issue of evaluation and control of the level of physical preparation of pupils. Such studies are conducted at school and university level as well. These authors (1) consider speed, strength and agility to be the leading factors of physical ability at a more 
mature age. The revealing of the factor structure of physical ability has high information value for the optimization of pupils' education process (2). Similar research was carried out in Macedonia and Romania (34). With the help of compulsory tests (four for preliminary and four for secondary schools) provided by the national system for the evaluation of physical education and sport, the dynamics and mobility of 7-14-year-old pupils was observed. It will be interesting to point out that only one of these tests made in Macedonia and Romania, coincides with those applied in Bulgaria, namely the long jump. The best results were recorded exactly along this test.

The analysis of the above facts, personal experiences and observations give us a reason to formulate the following working hypothesis: we assume that the present study will allow us to deduce directions for improvement of the educational process by $14-15$ year-old students.
The aim of the study is to improve the learning process of physical education in secondary school for students from VIII${ }^{m e}$ and IX ${ }^{\text {th, }}$ through analysis and evaluation of their physical capacity, under the new regulatory system for evaluation. We believe that this will help to optimize the educational process for physical education and sports in the next academic year.

\section{METHODS}

The study was carried out in January - March 2020

The research was aimed at studying the main and indexes of physical fitness of 14-15 yearold pupils (boys and girls) and was done among 36 pupils at a humanitarian secondary school.

For the purposes of research, we have tested pupils along 5 indexes that carry information about the major indexes of physical fitness presented in Table 1.

Table 1. Indicators examined

\begin{tabular}{|l|l|l|l|}
\hline No & Indexes & $\begin{array}{l}\text { Measure } \\
\text { unit }\end{array}$ & $\begin{array}{l}\text { Measurement } \\
\text { direction }\end{array}$ \\
\hline 1. & Running $30 \mathrm{~m}$ & $0.01 \mathrm{~s}$ & - \\
\hline 2. & Long jump with both feet from a place & $1.00 \mathrm{~cm}$ & + \\
\hline 3. & $\begin{array}{l}\text { 3 kg medicine ball throwing with both } \\
\text { hands from a standing position }\end{array}$ & $1.00 \mathrm{~cm}$ & + \\
\hline 4. & Running 200 m. & $0.01 \mathrm{~s}$ & - \\
\hline 5. & $\begin{array}{l}\text { Agility and space coordination test } \\
\text { (Hunting test) }\end{array}$ & $0.01 \mathrm{~s}$ & - \\
\hline
\end{tabular}

The four tests: Running $30 \mathrm{~m}$, Long jump with both feet from a place, $3 \mathrm{~kg}$ medicine ball throwing with both hands from a standing position and Running $200 \mathrm{~m}$ are standard tests applied in physical education and sport classes. The only new test is the Test for Agility and Spatial Coordination. Description: Four small rubber hoops $(15-20 \mathrm{~cm}$ in diameter) are placed in the shape of the letter $\mathrm{T}$ (Figure 1). There is one tennis ball in each hoop. Actions: the pupil stands in the front of the hoop at the start / finish spot in the initial position: upright, feet shoulder-width apart. At the starting signal, the pupil bends down, takes the ball from inside the hoop and moves to the rest of the hoops in the direction indicated by figures from 1 to 6 (Figure 1).

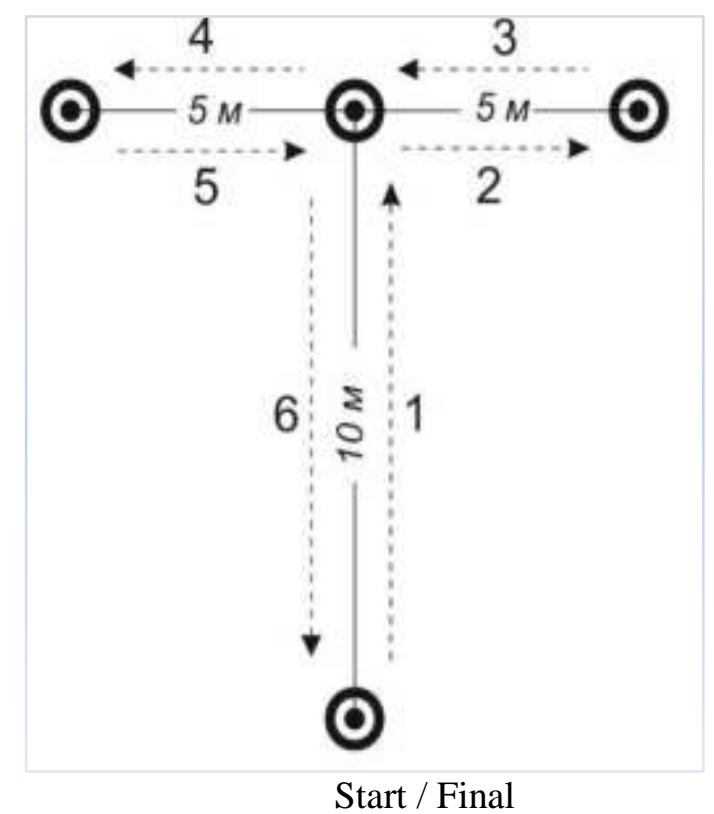

Figure 1. Hunting test 
Pupils take the ball from each hoop leaving the one they have taken from the previous hoop. The recording ends as soon as the ball touches the area of the hoop at the start / finishes point and is measured with an accuracy of up to $0.01 \mathrm{sec}$.

\section{Research methods and indexes}

In order to fulfill the set tasks and goals of the research we applied the following methods: $a$ detailed study of the specialized literature and sports-pedagogical testing.

Procedures. Sports-pedagogical tests were administered by the researcher in two sessions with 19 and 17 pupils during their regular classes. The testing was carried out by the school and the teachers of the researched individuals. Pupils' anonymity was guaranteed because all of them were recorded under different numbers. The respondents took part in the research voluntarily and did not receive any monetary or financial compensation for their contribution. None of the participants refused to take part. They were provided with brief instructions, video and demonstration. In standard settings - a gym and a running track in the school yard, with the necessary equipment: a stopwatch, measuring equipment and medicine ball - $3 \mathrm{~kg}$, each participant executed each test twice. In the analysis of the results, the better scores were used.

\section{Data analysis}

The results from the study were subjected to mathematical-statistical processing with SPSS 23; depending on the tasks of the research the following statistical methods were applied: descriptive statistics - for defining average values, normality of distribution and variety of indicators under study;

$\checkmark$ comparative analysis by t-criterion of Student for independent samples - for checking the reliability of differences between average levels of indicators under study between both groups - girls and boys. The critical value of the $\mathrm{t}$-criterion, at high statistical reliability $(\mathrm{Pt} \geq 95 \%)$, is $\mathrm{t}$. critical $=2.03$. That satisfies the needs of the sports practice (5);

$\checkmark$ comparative analysis of two independent samples with Man Whitney U-criterion on quantitative indicators with a distribution of values different from normal;

$\checkmark$ Signal deviation method - for the quantitative assessment of the condition of the measured signs. On the basis of the average level of the measured characteristics for a given age group, $\mathrm{T}$ estimates are calculated, which are normalized values presented in a 20-point system, which allows to compare the achievements in different dimensions tests and indicators (number, time, \%, etc.) The average of the whole population corresponds to 10 points.

\section{RESULTS}

The variational analysis used allows us to reveal the average level and variability of the signs of the physical capacity of the studied population. Table 2 summarizes the results of the applied variational analysis of grade 8 students.

Table 2. Averages and variability of the performance of students from VIII th grade-page 3

\begin{tabular}{|l|l|l|l|l|l|l|l|l|l|l|}
\hline No & Indexes & $\mathbf{N}$ & $\mathbf{R}$ & $\mathbf{m i n}$ & $\mathbf{m a x}$ & $\mathbf{X}$ & $\mathbf{S}$ & $\mathbf{A s}$ & $\mathbf{E x}$ & $\mathbf{V}$ \\
\hline 1. & Running 30 m & 17 & 3.13 & 7.47 & 4,34 & 5.48 & 1,001 & 1,086 &, 156 & 18,28 \\
\hline 2. & Long jump from place & 17 & 148 & 150 & 253 & 170.17 & 41,051 &, 925 &, 427 & 24.14 \\
\hline $\begin{array}{l}\text { 3 kg medicine ball } \\
\text { throwing }\end{array}$ & 17 & 435 & 380 & 815 & 545,58 & 130.07 &, 529 &, 653 & 23,84 \\
\hline 4. & Running 200 m & 17 & 30.32 & 62.92 & 32,60 & 45.61 & 9,274 &, 559 &, 426 & 20.33 \\
\hline 5. & Agility test & 17 & 8.37 & 19,95 & 11.58 & 14,61 & 2,570 &, 663 &, 612 & 17.61 \\
\hline
\end{tabular}

From the analysis of Table 2, it is clear that 17 students were examined, the distribution of values is normal and close to normal. Only with the Run $30 \mathrm{~m}$ indicator, the As values are above 1.00 . We think this is normal because the sample size is small $\mathrm{n} \leq 30$ and there are 9 boys and 8 girls in the class, which is a prerequisite for an asymmetric distribution of values according to this indicator. What strikes the analysis is that all values of the coefficient of variation "V" are above $10 \%$ in the range of $10 \%-30 \%$, which, according to sports statistics, shows that the population we study is relatively homogeneous on these grounds. The lowest is the value of $\mathrm{V}_{5}=17.61 \%$, this is the sign bearing the information about agility and speed of movement with change of direction. The highest values are $\mathrm{V}_{2}=24,12 \%$ 
and $\mathrm{V}_{3}=23,84 \%$, these are the signs related to the explosive power of the lower limbs and shoulder girdle and upper extremities.

Table 3 summarizes the results of the applied variational analysis of grade 9 students.

Analysis of Table $\mathbf{3}$ shows that 19 students were surveyed, the distribution of values is normal and close to normal on only two grounds, with the indicators "Running $30 \mathrm{~m}$ ", "Throwing a $3 \mathrm{~kg}$ square ball with two hands over head "and "Agility test" the values of As and Ex are well above \pm 1.00 . We believe that this is normal, because the volume of this sample is also low $\mathrm{n} \leq 30$, but in this class now have only 3 boys and 16 girls, which is a prerequisite for asymmetrical and different from the normal distribution of the values of these indicators. Here again, all values of the coefficient of variation "V" are above $10 \%$, but there is already an indicator that exceeds the limits of $10 \%-30 \%$ for a relatively homogeneous distribution $\left(\mathrm{V}_{3}=33,37 \%\right)$, which according to sports statistics shows that the set we are investigating is inhomogeneous on the basis of the strength of the shoulder girdle and upper limbs. In all other respects, the group studied by us is relatively homogeneous, with the lowest value observed at $\mathrm{V}_{4}=12.88 \%$, this is a sign related to the students' speed endurance.

Table 3. Mean values and variability of indicators of students in grade IX - page 3

\begin{tabular}{|l|l|l|l|l|l|l|l|l|l|l|}
\hline No & Indexes & $\mathbf{N}$ & $\mathbf{R}$ & $\mathbf{m i n}$ & $\mathbf{m a x}$ & $\mathbf{X}$ & $\mathbf{S}$ & As & $\mathbf{E x}$ & V \\
\hline 1. & Running 30 m & 19 & 3,32 & 7,80 & 4,48 & 5.09 &, 720 & 3,177 & 12,069 & 14.15 \\
\hline 2. & Long jump from place & 19 & 145 & 110 & 255 & 186.94 & 35,836 &, 268 &, 723 & 19,17 \\
\hline 3. & $\begin{array}{l}\text { 3 kg medicine ball } \\
\text { throwing }\end{array}$ & 19 & 710 & 350 & 1060 & 510.15 & 170,252 & 2,197 & 5,567 & 33.37 \\
\hline 4. & Running 200 m & 19 & 20,46 & 55.25 & 34.79 & 43.11 & 5,551 &, 645 &, 017 & 12,88 \\
\hline 5. & Agility test & 19 & 12 & 24 & 12 & 14.95 & 2,618 & 3,159 & 11,826 & 18,44 \\
\hline
\end{tabular}

Studies conducted with the same age group (6) have found that gender differences have a great influence on the physical capacity of students, and these differences are more pronounced in the explosive power of the lower and upper limbs, at speed opportunities and endurance of the children, the advantage being entirely on the boys side.

The applied variation analysis showed that both groups do not all have a normal distribution of values. Figure 2 presents a comparative analysis of class averages. By all indicators, grade 9 students have better scores. Only under the 5th "Agility test", the averages are very close.

For the needs of the study, each student is assessed on a gender and age basis. The students we study are between 13 and 15 years old.

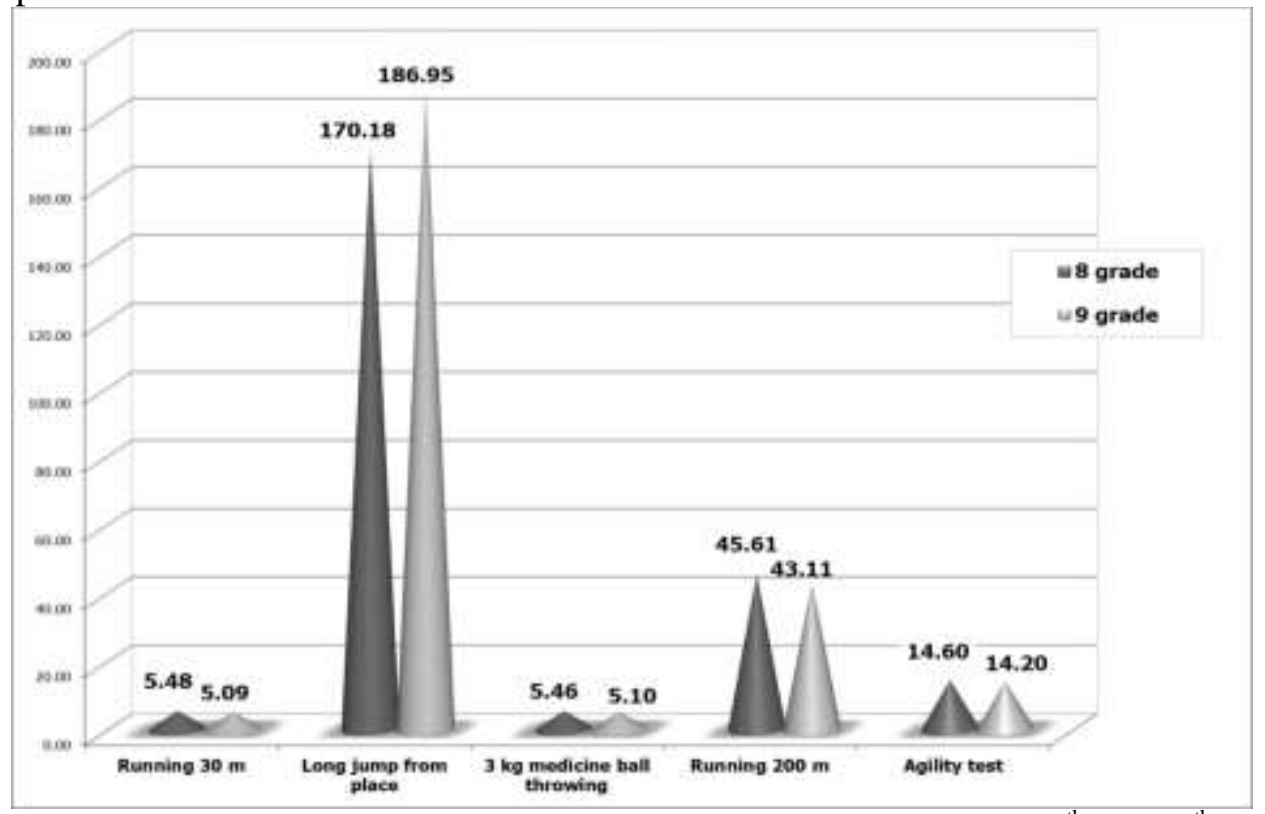

Figure 2. Comparative analysis of signs of physical fitness of students of VIII ${ }^{\text {th }}$ and IX ${ }^{\text {th }}$ grade 
As mentioned in the Student Assessment Methodology, a „System for assessing the physical capacity of students from I to XII grade" is applied in a 20-point scale, which allows to compare the achievements in differently sized tests and indicators (number, time, $\%$, etc.) The average level of the whole population corresponds to 8 to 14 points.

The analysis of the results presented in Figure 3 shows that for all the traits studied, students in grade 8 have lower grades.

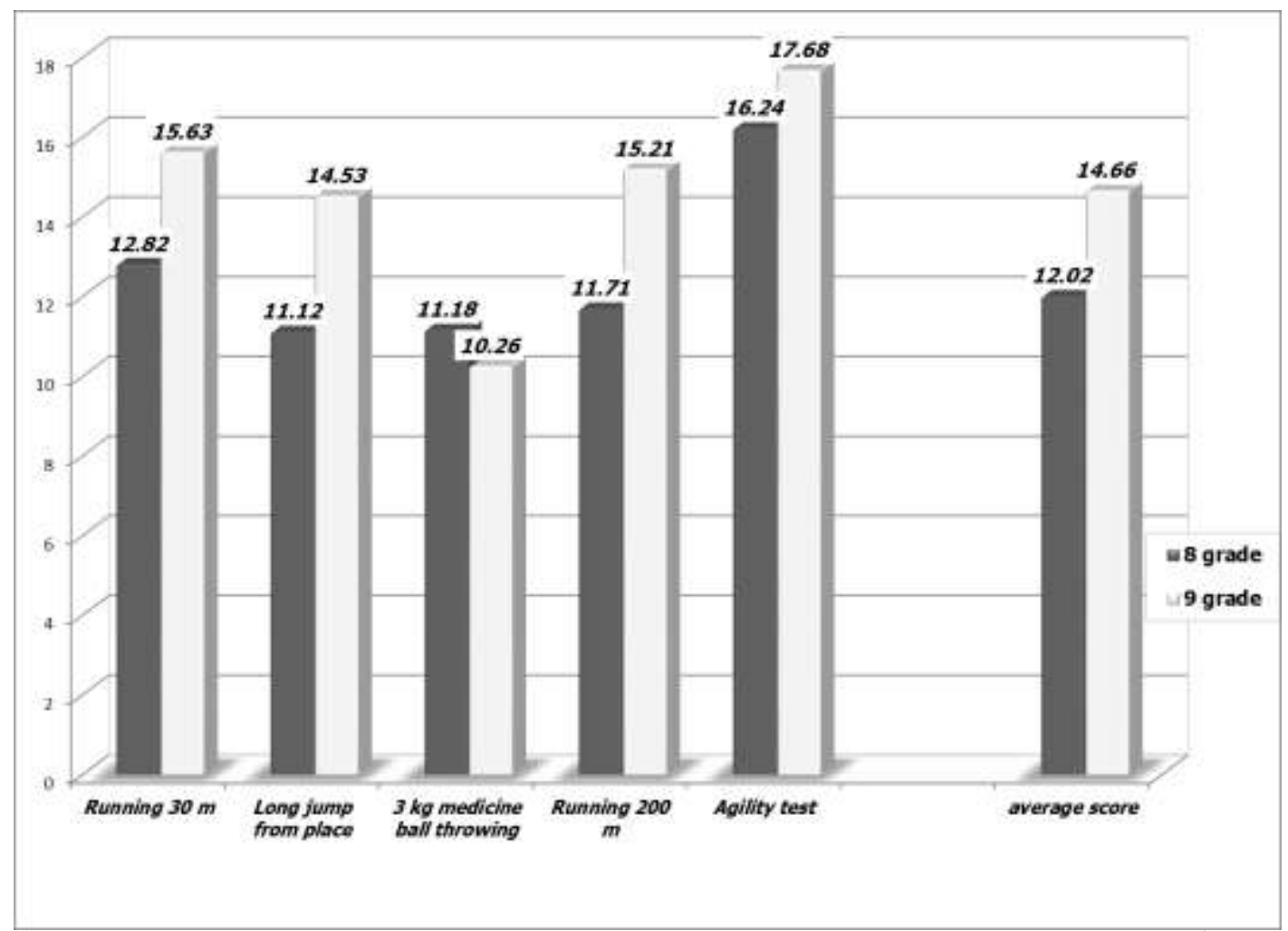

Figure 3. Comparative analysis of average scores on grounds of physical fitness of students of VIII ${ }^{\text {th }}$ and IX ${ }^{\text {th }}$ grade

The average scores for both groups are average for the country for the respective age (for grade 8 -12.02, for grade 9-14.66). Both groups receive an average grade of 4 .

However, the existence of certain differences between the mean scores on individual traits in the two classes studied does not allow us to draw any serious conclusions before verifying the validity of these differences. Comparative criteria were applied for this purpose: Student's T-test for independent samples, the critical value for the two compared sets for independent samples with guarantee probability $\mathrm{P} \geq 95$ is $\mathrm{t}=2.03$. For indicators where the distribution of values is different from normal, a U-Mann-Whitney criterion was applied.

No statistically significant difference was found in the benchmarking applied to any of the indicators. This gives us reason, with a high guarantee probability ( $\mathrm{P} \geq 95 \%$ ), to claim that there are no statistically significant differences in the students of the 8th and 9th grades in terms of physical capacity. All observed differences are due to random reasons.

The next step in our research was to determine whether in terms of gender in this age surveyed signs of individuals capacity has with existing statistical significant differences.

Table 4 presents a comparative analysis and the significance of differences between the two groups (girls and boys) in terms of physical performance.

The analysis of Table $\mathbf{4}$ shows that, in all, the indicator and the values of the $t$ criterion and a $\mathrm{U}$-criteria is higher than the critical s. This gives us a high guarantee probability to claim that at the age of 14-15 years, boys significantly outperform girls, in terms of all physical capacity tests examined. 
BORUKOVA M., et al.

Table 4. Comparative analysis of the mean values of the surveyed indexes of the two groups - page 4

\begin{tabular}{|c|c|c|c|c|c|c|c|c|c|c|c|c|c|}
\hline Indexes & Gender & $\mathrm{N}$ & Min & Max & $X$ & S & $\mathrm{V}$ & As & Ex & d & & $\mathrm{U}$ emp & $\alpha$ \\
\hline \multirow{2}{*}{$\begin{array}{l}\text { 1. Running } \\
30 \mathrm{~m}\end{array}$} & Boys & 13 & 4.34 & 5.64 & 4.82 & .41 & 8.53 & .807 & -.196 & -0.72 & & 2,783 & 0.005 \\
\hline & Girls & 23 & 4.72 & 7.80 & 5.53 & .96 & 17.43 & $1.47 *$ & .853 & & & & \\
\hline Indexes & Gender & $\mathrm{N}$ & Min & Max & $X$ & $S$ & V & As & Ex & d & $\begin{array}{l}\text { Cohen } \\
\text { d }\end{array}$ & t emp & $P(t)$ \\
\hline \multirow{2}{*}{$\begin{array}{l}\text { 2. Long } \\
\text { jump }\end{array}$} & Boys & 13 & 141 & 255 & 208.15 & 34.37 & 16.51 & -.338 & -.535 & 45.59 & 1.18 & 4.07 & 99.97 \\
\hline & Girls & 23 & 105 & 202 & 162.57 & 31.02 & 19.08 & -.587 & -.995 & & & & \\
\hline Indexes & Gender & $\mathrm{N}$ & Min & Max & $X$ & S & $\mathrm{V}$ & As & Ex & d & & U emp & $\alpha$ \\
\hline \multirow{2}{*}{$\begin{array}{l}3.3 \mathrm{~kg} \\
\text { medicine } \\
\text { ball } \\
\text { throwing }\end{array}$} & Boys & 13 & 400.00 & 1060.0 & 670.38 & 162.08 & 24.18 & .831 & 2.066 & 224.6 & & 4.331 & 0.000 \\
\hline & Girls & 23 & 350.00 & 530.00 & 445.78 & 56.21 & 12.61 & -.208 & -1.423 & & & & \\
\hline Indexes & Gender & $\mathrm{N}$ & Min & Max & $X$ & S & V & As & Ex & d & $\begin{array}{l}\text { Cohen } \\
\text { d }\end{array}$ & t emp & $P(t)$ \\
\hline \multirow{2}{*}{$\begin{array}{l}\text { 4. Running } \\
200 \mathrm{~m}\end{array}$} & Boys & 13 & 32.6 & 48.31 & 38.83 & 4.96 & 12.78 & .797 & -.279 & -8.541 & 1.13 & 3.86 & 99.95 \\
\hline & Girls & 23 & 39.74 & 62.92 & 47.37 & 7.02 & 14.83 & $.977 *$ & .065 & & & & \\
\hline Indexes & Gender & $\mathrm{N}$ & Min & Max & $X$ & $S$ & $\mathrm{~V}$ & As & Ex & d & & $\begin{array}{l}\mathrm{U} \\
\text { emp }\end{array}$ & $\alpha$ \\
\hline \multirow[t]{2}{*}{$\begin{array}{l}\text { 5. Agility } \\
\text { test }\end{array}$} & Boys & 13 & 11.58 & 18.27 & 12.95 & 1.75 & 13.54 & $2.6 *$ & $\begin{array}{l}7.898 \\
*\end{array}$ & -2.25 & & 3,458 & 0.001 \\
\hline & Girls & 23 & 12.74 & 24.00 & 15.20 & 2.63 & 17.29 & $\begin{array}{l}2.039 \\
*\end{array}$ & $\begin{array}{l}5.013 \\
*\end{array}$ & & & & \\
\hline
\end{tabular}

\section{DISCUSSION}

Both study groups are relatively homogeneous in most of the signs of physical ability. Students and both groups have the physical capacity of the average for the same age group in the country. Between the pupils of the VIII ${ }^{\text {th }}$ and IX ${ }^{\text {th }}$ class no statistically significant differences in individual characteristics. Although there are no statistically significant differences in classes on the different signs of physical abilities of students of VIII ${ }^{\text {th }}$ and IX ${ }^{\text {th }}$ should be noted that in general in the population surveyed students from ninth grade worsening performance. In a comparative analysis of the gender factor, it was shown that at this age boys are statistically significantly superior to girls of the same age group. In such a study (6), with one year younger students 1314 years, it is found that in terms of agility and ability to orient in space, there is no statistically significant difference between boys and girls, the existing differences between the two groups can be explained by random reasons. This gives us reason to say that within a year, age development has a greater impact on boys in terms of agility and orientation in space. Low physical activity among children aged $10-19$ is a serious problem. The results of conducted study shows that almost every day in their free time $48.2 \%$ of boys and $25.5 \%$ of girls are physically active, 2-3 times a week $33.8 \%$ of them are engaged in sports or other physical activity. Every third student is physically active once a week, less often or does not play sports at all, as the share of girls is almost twice as high as that of boys ( $38.6 \%$ vs. $20.0 \%$, respectively). Students aged 15-19 have lower physical activity in both sexes. The average duration of one physical activity session is also insufficient. Every fifth student exercises for about 30 minutes, which does not meet the WHO recommendations for physical activity in childhood. Children do not play sports mainly due to lack of desire, close and suitable place for it, and lack of training partner. The share of inactive children due to financial and health reasons is low (7).

\section{CONCLUSIONS}

The information and analysis derived from the study should be made available to the teacher and students. Efforts should be made to improve the level of physical fitness of all students participating in the study within the next academic year. In the process of training in physical education and sports, it's necessary to emphasize the importance of the physical capacity for the health status of the young generation. To stimulate both the active participation of students in physical education and sports lessons, as well as their participation 
in systemic extracurricular activities with exercise and sports.

Limitations of the study: The desire of the research team was to gather more information about students of the study age. Unfortunately, the situation of a flu vacation and then a pandemic in the country and in the world forced our research to cease and we limited ourselves to processing and analyzing only the data collected until 13.03.2020 information.

Acknowledgments: This article is the result of the collaborative work of the authors, PE teachers working with the students studied. The authors appreciate the efforts of all involved in this study.

\section{REFERENCES}

1. Miladinov et all., System for assessing the physical capacity of students from I to XII grade. NSA Pres, Sofia, ISBN 978-954718-570-8. pp. 14, 2019.

2. Tzarova, R., Borukova, M., Preparedness study of students applying for sports schools with a basketball profile. Sports \& Science, ISSN 1310-3303, (Izv.issue 2.) pp. 89-97.2011.

3. Bădicu, G., The dynamics of mobility in the light of the assessment of mandatory tests, introduced in the national system of evaluation, in students in primary and second educational stages. Journal Plus Education. ISSN 1842-077X, E-ISSN (online) 2068-1151, vol.XVIII, pp.112-121. 2017

4. Bujar, S., Tables For Evaluation Of The Motor Capabilities Of 10 Years Old Male Pupils In Rebublic Of Macedonia, FIEP BULLETIN. Volume 83 -Special Edition ARTICLE III, pp. 340-342. 2013.
5. Gigova, V., Statistical processing and analysis of data . Practical Guide for Master's Students. NSA, S., 1999.

6. Borukova, M.,- Factor Structure and Major Factors of Physical Ability of 13-14-YearOld Pupils, Journal of Applied Sports Sciences, Vol.1, ISSN 2534-9597 (Print), ISSN 2535-0145 (Online), DOI: 10.37393/jass.2019.01.7. pp. 77-84. 2019.

7. Kirilova, I., Andonov, St., Health factors physical activity.Scientific and applied research conference.Book of proceedings, Sofia, pp.21-38, 2019.

8. Borukova, M., Management and control of sports preparation of 14-15-year-old female basketball players, Journal of Applied Sports Sciences, Vol.2, pp. 19-30 ISSN 2534-9597 (Print), ISSN 2535-0145 (Online) DOI: 10.37393 / jass.2017.02.3.2017.

9. Borukova, M., Control of sports training at 13-14 year old basketball players. Sofia, Bolid ins. ISBN 978-954-394-242-8, 2018.

10. Borukova, M., Factor structure and basic factors of physical development and specific workability of growing up basketball players (12-19 years old). Physical Education and Sport, Competition for Life, 9-12 October, . pp. 287-296. 2014.

11. Coelho-e-Silva, Manuel \& Figueiredo, António \& Carvalho, Humberto \& Malina, Robert., Functional capacities and sportspecific skills of 14- to 15-year-old basketball players: Size and maturity effects. Eur $J$ Sport Sci. 8. pp. 277285.DOI:10.1080/ 17461390802117177. 2008. 